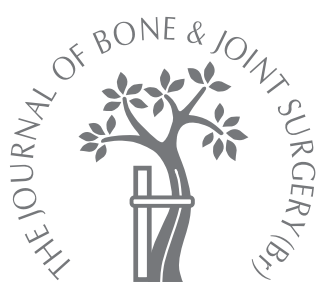

J. K. Seon,

S. J. Park,

T. R. Yoon,

K. B. Lee,

E. S. Moon,

E. K. Song

From Chonnam

National University

Hwasun Hospital,

Hwasun, South

Korea

\section{The effect of anteroposterior laxity on the range of movement and knee function following a cruciate-retaining total knee replacement}

The amount of anteroposterior laxity required for a good range of movement and knee function in a cruciate-retaining total knee replacement (TKR) continues to be debated. We undertook a retrospective study to evaluate the effects of anteroposterior laxity on the range of movement and knee function in $\mathbf{5 5}$ patients following the e-motion cruciateretaining TKR with a minimum follow-up of two years. The knees were divided into stable (anteroposterior translation, $\leq 10 \mathrm{~mm}, 38$ patients) and unstable (anteroposterior translation, $>10 \mathrm{~mm}, 17)$ groups based on the anteroposterior laxity, measured using stress radiographs. We compared the Hospital for Special Surgery (HSS) scores, the Western Ontario MacMasters University Osteoarthritis (WOMAC) index, weight-bearing flexion, nonweight-bearing flexion and the reduction of flexion under weight-bearing versus nonweight-bearing conditions, which we referred to as delta flexion, between the two groups at the final follow-up.

There were no differences between the stable and unstable groups with regard to the mean HHS and WOMAC total scores, as well as weight-bearing and non-weight-bearing flexion ( $p=0.277, p=0.082, p=0.095$ and $p=0.646$, respectively). However, the stable group had a better WOMAC function score and less delta flexion than the unstable group $(p=0.011$ and $p=0.005$, respectively).

Our results suggest that stable knees with laxity $\leq 10 \mathrm{~mm}$ have a good functional outcome and less reduction of flexion under weight-bearing conditions than unstable knees with laxity $>10 \mathrm{~mm}$ following an e-motion cruciate-retaining TKR.

\footnotetext{
J. K. Seon, MD, PhD, Orthopaedic Surgeon S. J. Park, MD, PhD Orthopaedic Surgeon

a. R. Yoon, MD, PhD,

Professor

E. K. Song, MD, PhD, Orthopaedic Surgeon,

Professor

Department of Orthopaedic

Surgery, Center for Joint

Disease

Chonnam National University, Hwasun Hospital, 160 ilsimri, Hwasun, South Korea.

K. B. Lee, MD, PhD, Professor E. S. Moon, MD, PhD,

Professor

Department of Orthopaedics Chonnam National University Hospital, 8 Hakdong, Gwangju,
} Korea.

Correspondence should be sent to Professor E. K. Song; e-mail: eksong@chonnam.ac.kr

(C)2010 British Editorial Society of Bone and Joint Surgery doi:10.1302/0301-620X.92B8 $23980 \$ 2.00$

$J$ Bone Joint Surg [Br] 2010;92-B:1090-5.

Received 26 February 2010;

Accepted after revision 15 April 2010
The range of movement (ROM) under weightbearing conditions after total knee replacement (TKR) is an important indicator of outcome. Although TKR provides a good ROM in the knee under non-weight-bearing conditions, ${ }^{1-5}$ some studies have reported that, under weightbearing conditions like squatting or single-leg lunge activities, the ROM was decreased compared with that under non-weight-bearing conditions after a cruciate-retaining TKR. ${ }^{4-6}$ It has been speculated that this results from a decreased posterior femoral roll-back because of an ineffective posterior cruciate ligament (PCL) causing instability. $3,7,8$

Many factors influence the anteroposterior (AP) laxity of a replaced knee. These include the geometry, the size and positioning of the prosthesis, soft-tissue balance and the posterior tibial slope. ${ }^{9}$ However, the functional status of the PCL may also play an important role in AP stability after a cruciate-retaining TKR. Some studies have questioned the role of the retained PCL in this situation. ${ }^{10-12}$ Furthermore, the amount of AP laxity required for good ROM and function after a cruciateretaining TKR, continues to be debated..$^{10,13-19}$ While studies have reported that a moderate AP laxity of $5 \mathrm{~mm}$ to $10 \mathrm{~mm}$ may provide a better movement and improved function, compared with a knee that is too tight or too loose, ${ }^{9,16}$ some studies have shown a strong positive correlation between AP laxity and ROM, suggesting that lax knees following a TKR had a better ROM. ${ }^{13,16,20}$

Our aim, therefore, was to evaluate the effects of AP laxity on weight-bearing and ROM following a cruciate-retaining TKR. In addition, we wished to establish the correlation between AP laxity, ROM and function.

\section{Patients and Methods}

This is a retrospective study of 55 patients who underwent a primary cruciate-retaining TKR using computer-assisted navigation for degenerative osteoarthritis from January 2005 to September 2007. Patients who had a postoperative $\mathrm{ROM}$ of $\leq 90^{\circ}$ or those with a previous history of open knee surgery prior to the 
TKR were excluded. There were nine men and 46 women with a mean age of 68.2 years $(55.0$ to 81.0$)$ at the time of surgery. The mean follow-up period was 33 months $(24.0$ to 52.0). Ethical approval was granted for the study and informed consent was obtained from all the patients.

Surgical technique. The TKRs were performed by the senior author (EKS) using a medial parapatellar arthrotomy with patellar eversion and the Orthopilot version 4.08 computer-assisted navigation system (Aescalup, Tuttlingen, Germany).

After removing all osteophytes and performing the proximal tibial osteotomy at $0^{\circ}$ in the coronal and the sagittal planes, adequate medial soft-tissue release was performed to achieve collateral ligament balance. The goal was to adjust the collaterals so that they were balanced to within $2^{\circ}$ to $3^{\circ}$ in extension. A distractor which had two flat independent plates for the medial and the lateral compartments was used to measure the gaps in extension after adequate ligament release. After recording the extension gaps, the distractor was placed in the joint at $90^{\circ}$ of flexion and the flexion gaps were recorded. The distal femoral cutting block was placed for a cut perpendicular to the tibial shaft axis in the coronal and the sagittal planes and the cut was completed. The 4-in-1 cutting block was then placed for the chamfer cut, which was performed to equalise the flexion and the extension gaps. A variation in the mediolateral and the AP laxity of less than $2^{\circ}$ to $3^{\circ}$ after a trial insertion was confirmed in order to determine the required thickness of the polyethylene insert. The PCL was retained and a cemented e-motion prosthesis (Aesculap) was implanted with cement. The e-motion is a mobile bearing cruciate retaining prosthesis which achieves a large contact area, and its femorotibial articulation has a somewhat conforming design. The tibial base plate has a posterior slope of $3^{\circ}$ and the polyethylene insert is slightly dished in the sagittal plane with a slightly elevated anterior tip.

Clinical evaluation. The knees were divided into stable $(<10 \mathrm{~mm}, 38)$ and unsable $(\geq 10 \mathrm{~mm}, 17)$ groups based on the total AP laxity. The Hospital for Special Surgery (HSS) ${ }^{21}$ score and the Western Ontario MacMasters University (WOMAC) ${ }^{22}$ osteoarthritis index were measured and nonweight-bearing and weight-bearing flexion radiographs were obtained in each patient at the final follow-up. In addition, the delta flexion was calculated as the difference in flexion while the patient was non-weight-bearing and weight-bearing. The former was measured with the patient in the supine position and the latter during a single-leg lunge, using a goniometer. One arm of the goniometer was placed parallel to the shaft of the femur, which was estimated from the location of the greater trochanter and the lateral femoral condyle, and the other arm parallel to the shaft of the tibia, which was estimated from the fibular head and the lateral malleolus. ${ }^{7}$ All the ROMs and clinical data were evaluated and recorded by a physiotherapy assistant.

Radiological evaluation. In order to evaluate post-operative stability, the AP laxity at $90^{\circ}$ of knee flexion was measured using anterior and posterior stress lateral radiographs taken in the lateral decubitus position (with a $9 \mathrm{~kg}$ load) with a Telos arthrometer (Austin and Associate Inc., Fallston, Maryland). Measurements of the AP laxity were obtained by tracing a line along the posterior border of the tibial component and then measuring the perpendicular distance to a point marked at the most posterior part of the posterior condyle on the femoral component (Fig. 1). The total AP laxity was calculated as the sum of the anterior and posterior laxity, because the resting position of the femoral component, in relation to the tibial component, varied. One observer (SJP), who was blinded to the patient's clinical outcome, performed the testing and measurements at the final follow-up.

The correlation between the total AP laxity and the three ROM parameters (weight-bearing, non-weight-bearing, and delta flexion) was evaluated as well as that between the total AP laxity and the HSS and WOMAC scores. There were no significant differences between the stable and the unstable groups with regard to the age at surgery, gender, the duration of follow-up and the body mass index (Table I).

The radiological indices measured included the femorotibial angle on the standing AP radiographs and the posterior slope of the tibia on the lateral radiographs obtained at the final follow-up. In addition, the difference in the posterior femoral condylar offsets pre-operatively was compared with that at the final follow-up. The posterior femoral condylar offset was evaluated by measuring the maximum thickness of the posterior femoral condyle projected posteriorly to the tangent of the posterior cortex of the femoral shaft on lateral radiographs. ${ }^{23}$ In order to obtain accurate lateral views, these exposures were adjusted throughout the investigation under fluoroscopic control. All the measurements were performed by a resident (SJP) who was unaware of the results and the clinical outcome.

Statistical analysis. The sample size was determined based on values which were derived from the first 20 patients. With mean values of delta flexion of $7.7^{\circ}\left(0^{\circ}\right.$ to $\left.15^{\circ}\right)$ for the stable group and of $12.5^{\circ}\left(5^{\circ}\right.$ to $\left.20^{\circ}\right)$ for the unstable group, it was determined that a total of 17 knees would be needed in the unstable group to show a significant difference with a power $(1-\beta)$ of $80 \%(\alpha=0.05)$. Statistical comparison of the clinical outcome, flexion parameters and total laxity between the two groups was carried out using the MannWhitney $U$ test. The correlation between laxity and the flexion parameters was analysed using Pearson's correlation coefficient. All the analyses were performed using SPSS version 16.0 (SPSS Inc., Chicago, Illinois) with statistical significance set at a $\mathrm{p}$-value $\leq 0.05$.

\section{Results}

The mean AP laxity was $7.6 \mathrm{~mm}(0.6$ to 9.5$)$ in the stable group and $13.1 \mathrm{~mm}$ (10.2 to 15.3 ) in the unstable group. The mean pre-operative HSS and WOMAC scores, as well as the flexion parameters showed no significant difference between the two groups (Tables I and II). The mean post- 


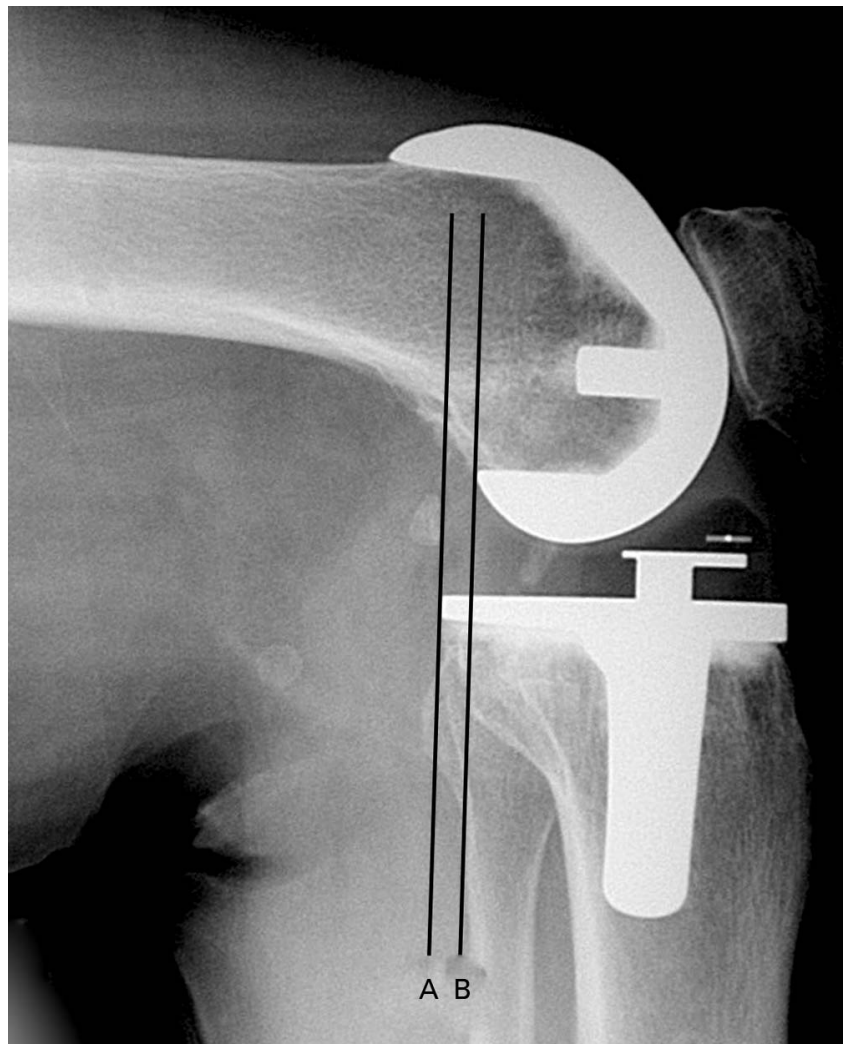

Fig. 1a

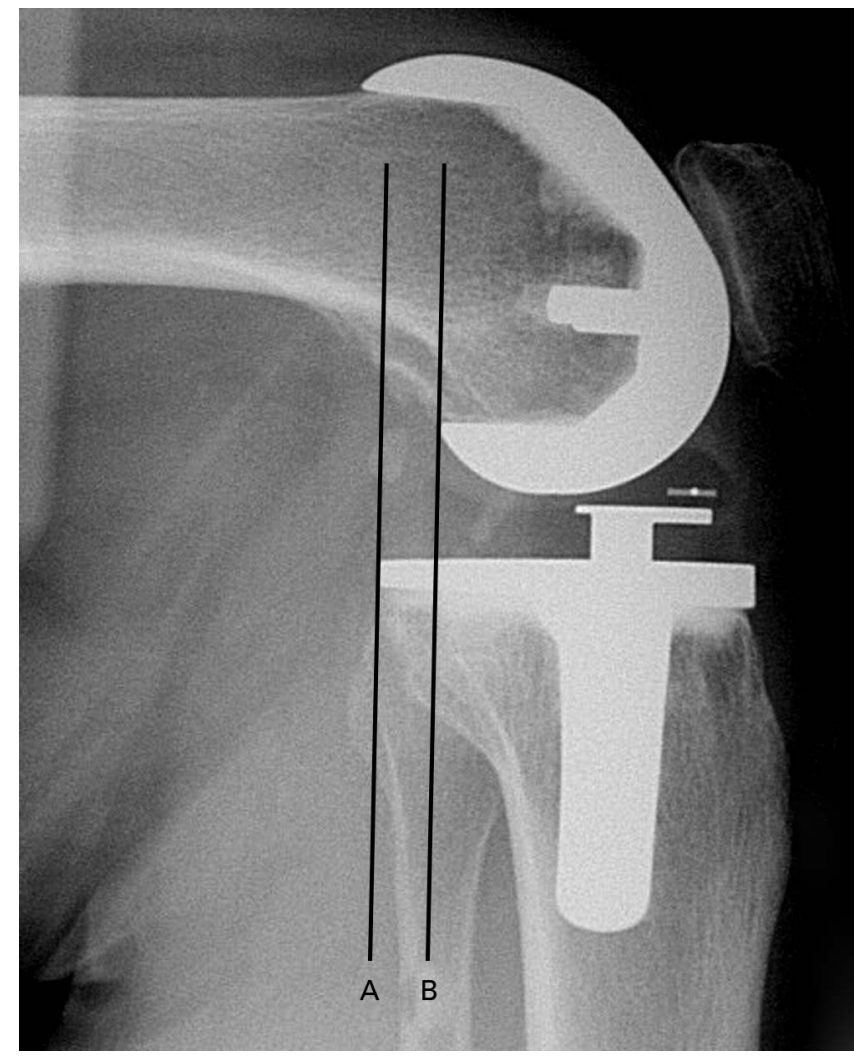

Fig. 1b

Anterior (a) and posterior (b) stress radiographs showing the measurement of the total anteroposterior laxity (difference of anterior and posterior displacement). Displacement was defined as the perpendicular distance between a line along the posterior border of the tibial component (A) and line at the most posterior part of the femoral component posterior condyle (B).

Table I. Comparison of pre-operative and post-operative details (mean, range) and knee function in the two groups

\begin{tabular}{|c|c|c|c|}
\hline & Stable group $(n=38)$ & Unstable group $(n=17)$ & p-value \\
\hline Age in years & 68.0 (55 to 77$)$ & 68.8 (57 to 81$)$ & 0.855 \\
\hline Men:women & $6: 32$ & 3:14 & 0.863 \\
\hline \multicolumn{2}{|c|}{ Duration of follow-up in months 33.3 (24 to 52 ) } & 32.4 (24 to 48$)$ & 0.963 \\
\hline Body mass index $\left(\mathrm{kg} / \mathrm{m}^{2}\right)$ & 25.3 (18 to 37$)$ & 25.8 (19 to 37$)$ & 0.509 \\
\hline \multicolumn{4}{|l|}{ HSS $^{*}$ score } \\
\hline Pre-operative & 63.2 (44 to 77 ) & 64.6 (48 to 79 ) & 0.663 \\
\hline Post-operative & 91.4 (80 to 100$)$ & 89.8 ( 80 to 98 ) & 0.277 \\
\hline \multicolumn{4}{|l|}{ WOMAC $^{\dagger}$ score total } \\
\hline Pre-operative & 73.8 (59 to 100$)$ & $72.0(57$ to 95$)$ & 0.368 \\
\hline Post-operative & 29.2 (24 to 43$)$ & $31.2(27$ to 42$)$ & 0.082 \\
\hline Function, pre-operative & 50.4 (40 to 65$)$ & 50.8 (40 to 69$)$ & 0.552 \\
\hline Post-operative & $19.8(17$ to 30$)$ & 21.6 (19 to 28$)$ & 0.011 \\
\hline
\end{tabular}

* HSS, Hospital for Special Surgery

† WOMAC, Western Ontario and Macmasters University osteoarthritis index

operative non-weight-bearing maximum flexion was similar in the stable and unstable groups, $130.3^{\circ}\left(110^{\circ}\right.$ to $\left.140^{\circ}\right)$ and $132.1^{\circ}\left(100^{\circ}\right.$ to $\left.140^{\circ}\right)$ respectively (MannWhitney, $\mathrm{p}=0.646$, Table II). In addition, there was no significant difference between the groups in the mean weight-bearing maximum flexion (Mann-Whitney, $\mathrm{p}=0.095$, Table II). The mean delta flexion was significantly less in the stable group compared with the unstable 
Table II. Comparisons of pre-operative and post-operative range of movement (mean, range) in the two groups

\begin{tabular}{|c|c|c|c|}
\hline & Stable group $(n=38)$ & Unstable group ( $n=17$ ) & p-value \\
\hline \multicolumn{4}{|c|}{ Pre-operative flexion } \\
\hline NWB $^{*}$ & 127.9 (80 to 140$)$ & 123.8 (80 to 140$)$ & 0.302 \\
\hline$W^{\dagger}$ & $123.0(80$ to 140$)$ & 117.4 (80 to 135 ) & 0.254 \\
\hline Delta & $4.1(-5$ to 20$)$ & $5.3(0$ to 20$)$ & 0.440 \\
\hline \multicolumn{4}{|c|}{ Post-operative flexion } \\
\hline NWB & $130.3(95$ to 140$)$ & 132.1 (110 to 140$)$ & 0.646 \\
\hline WB & 120.5 (85 to 140$)$ & 115.9 (100 to 130$)$ & 0.095 \\
\hline Delta & $9.7(0$ to 25$)$ & $16.2(5$ to 30$)$ & 0.005 \\
\hline
\end{tabular}

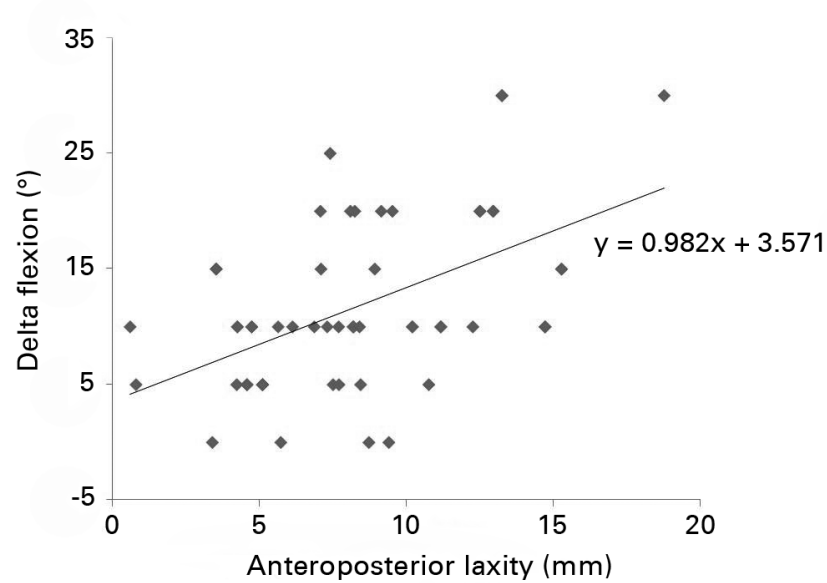

Fig. 2

Scattergram showing a positive correlation between delta flexion and the anteroposterior laxity.

group $\left(9.7^{\circ}\left(0^{\circ}\right.\right.$ to $\left.25^{\circ}\right)$ versus $16.2\left(5^{\circ}\right.$ to $\left.20^{\circ}\right)$; MannWhitney, $\mathrm{p}=0.005$, Table II). While the mean HSS and the mean total WOMAC scores showed no significant difference between the groups, the stable group had a better mean post-operative WOMAC function score compared with the unstable group $\left(19.8^{\circ}\left(17^{\circ}\right.\right.$ to $\left.30^{\circ}\right)$ versus $21.6^{\circ}$ $\left(19^{\circ}\right.$ to $\left.28^{\circ}\right)$; Mann-Whitney, $\mathrm{p}=0.011$, Table I).

No correlation was found between the AP laxity and the non-weight-bearing $(\mathrm{r}=0.06, \mathrm{p}=0.645)$ and the weight-bearing maximal flexion $(\mathrm{r}=0.26, \mathrm{p}=0.056)$. However, there was a significant correlation between the delta flexion and AP laxity $(\mathrm{r}=0.51, \mathrm{p}<0.001$, Fig. 2). The HSS and the WOMAC scores showed no significant correlation with the AP laxity $(\mathrm{r}=0.29, \mathrm{p}=0.125$ and $\mathrm{r}=0.13, \mathrm{p}=0.346$, respectively).

The mean femorotibial angle measured at the final followup was $5.3^{\circ}\left(0^{\circ}\right.$ to $\left.10^{\circ}\right)$ of valgus in the stable group and $4.7^{\circ}$ $\left(1^{\circ}\right.$ to $\left.9^{\circ}\right)$ of valgus in the unstable group, which was not significant (Mann-Whitney, $\mathrm{p}=0.511$ ). The mean posterior tibial slope at the final follow-up and the mean change in the posterior femoral condylar offset after TKR were also simi$\operatorname{lar}\left(2.5^{\circ}\left(-1^{\circ}\right.\right.$ to $\left.7^{\circ}\right)$ in the stable and $2.2^{\circ}\left(0^{\circ}\right.$ to $\left.5^{\circ}\right)$ in the unstable group; $1.1 \mathrm{~mm}(-4 \mathrm{~mm}$ to $7 \mathrm{~mm})$ in the stable and $1.5 \mathrm{~mm}(-3 \mathrm{~mm}$ to $5 \mathrm{~mm})$ in the unstable group, $\mathrm{p}=0.702$ and $\mathrm{p}=0.614$, respectively (both Mann-Whitney)).

\section{Discussion}

We evaluated the effects of the AP laxity on the three flexion parameters (weight-bearing, non-weight-bearing and delta flexion) as well as the clinical outcome following cruciate-retaining TKR. Our results showed that stable knees had less delta flexion and better function than unstable knees. A significant correlation was found between the delta flexion and the AP laxity, but there was no significant correlation between the HSS or the WOMAC scores and AP laxity.

Several studies ${ }^{3-5,8}$ have shown a significant decrease in weight-bearing flexion compared with the non-weightbearing flexion, although various activities for weightbearing flexion such as a single-leg lunge, squatting or kneeling have been used in different studies. This decrease in flexion under weight-bearing conditions following cruciateretaining TKR may have been because of abnormal knee kinematics caused by a decreased femoral roll-back. It has been shown that following this procedure the femorotibial contact is translated anteriorly with increasing knee flexion. ${ }^{6,8}$ In our study, the weight-bearing flexion during a single-leg lunge activity and active non-weight-bearing flexion in the supine position were measured. The results of a decrease in flexion, under weight-bearing conditions, were comparable with those of other studies reporting on the outcome following cruciate-retaining TKR. ${ }^{3-5}$

A number of studies have attempted to evaluate laxity following cruciate-retaining TKR. One of the problems with the data from these studies is that various instruments and angles have been used for measuring laxity. Another problem is that the definition of the neutral position when measuring anterior and posterior displacement is varied. In our study, the total AP laxity was measured as the sum of the anterior and posterior laxity at $90^{\circ}$ of flexion using a 
Telos device (Austin and Associate Inc). The results showed a mean $8.3 \mathrm{~mm}$ of total AP laxity and more than $10 \mathrm{~mm}$ in one-third of patients, at a minimum follow-up of two years. Matsuda et $a{ }^{10}{ }^{10}$ using a KT-2000 arthrometer at $75^{\circ}$ of flexion, reported a laxity of $8.1 \mathrm{~mm}$ and of more than $10.0 \mathrm{~mm}$ in half the knees in their series of cruciateretaining TKRs. In addition, Ishii et $\mathrm{al}^{13}$ reported AP laxity of $4.5 \mathrm{~mm}$ at $75^{\circ}$ of flexion.

Many studies have examined the relationship between AP laxity and the ROM or clinical outcome..$^{10,13-20,24} \mathrm{~A}$ better post-operative ROM with less pain in patients with stable knee prostheses has been described in some reports ${ }^{13,19,20}$ whereas others have found a better functional outcome and ROM in knees with a lax prostheses. $^{14,16}$ Most studies ${ }^{10,13-20,24}$ have evaluated the relationship between AP laxity and passive or non-weightbearing ROM. However, the weight-bearing ROM is more important for the function of the knee following a TKR. It is well known ${ }^{3-5,8}$ that weight-bearing flexion of the knee is significantly decreased compared with non-weight-bearing flexion following a TKR, especially following a cruciateretaining TKR, but there are variations in the way in which weight-bearing flexion has been evaluated. With our method of evaluation no differences were found between the stable and the unstable groups in terms of non-weight-bearing and weight-bearing flexion. However, the stable knees with less than $10 \mathrm{~mm}$ of AP laxity had a smaller delta flexion compared with the unstable knees $\left(9.7^{\circ}\right.$ versus $16.2^{\circ}$ in stable and unstable knee groups, respectively). These findings are similar to the results of Matsuda et al ${ }^{10}$ and Ishii et al. ${ }^{13}$ In both studies a total AP laxity of $9 \mathrm{~mm}$ to $10 \mathrm{~mm}$ was found in wellfunctioning mobile knees and this amount of laxity was recommended at $30^{\circ}$ flexion in the knee.

While Yamakado et $\mathrm{al}^{19}$ found no correlation in cruciateretaining TKR knees between AP laxity and the HSS score, with a mean total AP laxity of $9.7 \mathrm{~mm}$ at $30^{\circ}$ of flexion, Warren et $\mathrm{a}^{20}$ found that anterior laxity of more than $10 \mathrm{~mm}$ had a poorer outcome when measured using the Knee Society functional score after cruciate-retaining TKR at follow-up of three to four years. We found that stable knees $(\leq 10.0 \mathrm{~mm})$ after cruciate-retaining TKR had a better WOMAC function score than unstable knees. Concerning the relationship between the AP laxity and flexion parameters, only delta flexion showed a significant positive correlation with AP laxity $(r=0.51)$. However, no significant differences between the two groups with regard to the HSS and WOMAC total scores were found. Moreover, the mean HSS and the mean WOMAC scores showed no significant correlation with AP laxity, $(\mathrm{p}=0.125$ and $\mathrm{p}=0.346$ respectively).

Massin and Gournay ${ }^{23}$ investigated the potential effects of the posterior femoral condylar offset and tibial slope on the range of knee flexion and showed that a decrease in the posterior condylar offset of $3 \mathrm{~mm}$ reduced flexion by $10^{\circ}$ before tibiofemoral impingement occurred. Furthermore, a simultaneous decrease in the tibial slope of $5^{\circ}$ reduced the range of flexion by a further $5^{\circ}$. However, our results have shown that there was no significant difference in the change in the posterior femoral condylar offset following a TKR and the tibial posterior slope at the final follow-up between the two groups.

We recognise the limitations of our study. First, there is a potential for bias because of its retrospective nature. However, it should be noted that a prospective study is difficult to carry out because it is difficult to predict how much laxity patients will have following surgery, which would make a power analysis difficult. Secondly, laxity was evaluated only for one type of cruciate-retaining implant. Hence, laxity of $10 \mathrm{~mm}$ may not be appropriate for other cruciateretaining designs, because it can be influenced by complex interactions between the implant and the soft-tissue structures which surround the knee. Thirdly, the ROM was measured in all the patients by one physiotherapy assistant using a goniometer rather than radiographs. However, several studies have reported on the reproducibility of measurements obtained with a goniometer and have shown a high intra- and inter-observer correlation. ${ }^{25,26}$ Therefore, the flexion data were deemed to be reliable and suitable for the purpose of this comparative study.

In conclusion, stable knees (AP laxity $\leq 10 \mathrm{~mm}$ ) showed a better functional outcome and less reduction of flexion under weight-bearing conditions compared with unstable knees (AP laxity $>10.0 \mathrm{~mm}$ ), following a cruciate-retaining TKR. Moreover, reduction of flexion under weight-bearing conditions was significantly related to the AP laxity. Based on our results, laxity of more than $10.0 \mathrm{~mm}$ after e-motion TKR should be avoided if a good functional outcome including flexion under weight-bearing conditions is to be achieved.

No benefits in any form have been received or will be received from a commercial party related directly or indirectly to the subject of this article.

\section{References}

1. Bin SI, Nam TS. Early results of high-flex total knee arthroplasty: comparison study at 1 year after surgery. Knee Surg Sports Traumatol Arthrosc 2007;15:350-5.

2. Chaudhary R, Beaupre LA, Johnston DW. Knee range of motion during the first two years after use of posterior cruciate-stabilizing or posterior cruciate-retaining total knee prostheses: a randomized clinical trial. J Bone Joint Surg [Am] 2008;90A:2579-86.

3. Dennis DA, Komistek RD, Stiehl JB, Walker SA, Dennis KN. Range of motion after total knee arthroplasty: the effect of implant design and weight-bearing conditions. J Arthroplasty 1998;13:748-52.

4. Kim YH, Choi Y, Kwon OR, Kim JS. Functional outcome and range of motion of high-flexion posterior cruciate-retaining and high-flexion posterior cruciate-substituting total knee prostheses: a prospective, randomized study. J Bone Joint Surg [Am] 2009;91-A:753-60.

5. Seon JK, Park SJ, Lee KB, et al. Range of motion in total knee arthroplasty: a prospective comparison of high-flexion and standard cruciate-retaining designs. J Bone Joint Surg [Am] 2009;91-A:672-9.

6. Dennis DA, Komistek RD, Scuderi GR, Zingde S. Factors affecting flexion after total knee arthroplasty. Clin Orthop 2007;464:53-60.

7. Dennis DA, Komistek RD, Mahfouz MR, Haas BD, Stiehl JB. Multicenter determination of in vivo kinematics after total knee arthroplasty. Clin Orthop 2003;416:37-57.

8. Victor J, Banks S, Bellemans J. Kinematics of posterior cruciate ligament-retaining and -substituting total knee arthroplasty: a prospective randomised outcome study. J Bone Joint Surg [Br] 2005;87-B:646-55.

9. Bellemans J, Robijns F, Duerinckx J, Banks S, Vandenneucker H. The influence of tibial slope of maximal flexion after total knee arthroplasty. Knee Surg Sports Traumatol Arthrosc 2005;13:193-6.

10. Matsuda S, Miura H, Nagamine R, et al. Knee stability in posterior cruciate ligament retaining total knee arthroplasty. Clin Orthop 1999;366:169-73. 
11. Nabeyama R, Matsuda S, Miura H, et al. Changes in anteroposterior stability following total knee arthroplasty. J Orthop Sci 2003;8:526-31.

12. Misra AN, Hussain MR, Fiddian NJ, Newton G. The role of the posterior cruciate ligament in total knee replacement. J Bone Joint Surg [Br] 2003;85-B:389-92

13. Ishii Y, Matsuda Y, Ishii R, Sakata S, Omori G. Sagittal laxity in vivo after total knee arthroplasty. Arch Orthop Trauma Surg 2005;125:249-53.

14. Itokazu M, Masuda K, Wada E, et al. Influence of anteroposterior and mediolateral instability on range of motion after total knee arthroplasty: an ultrasonographic study. Orthopedics 2000;23:49-52.

15. Jones DP, Locke C, Pennington J, Theis JC. The effect of sagittal laxity on function after posterior cruciate-retaining total knee replacement. J Arthroplasty 2006;21:719-23.

16. Seon JK, Song EK, Yoon TR, et al. In vivo stability of total knee arthroplasty using a navigation system. Int Orthop 2007;31:45-8.

17. van Hal CT, van Hellemondt GG, Wymenga AB, Jacobs WC. The anterior-posterior laxity after total knee arthroplasty inserted with a ligament tensor. Knee Surg Sports Traumatol Arthrosc 2007;15:1019-22.

18. White SH, O'Connor JJ, Goodfellow JW. Sagittal plane laxity following knee arthroplasty. J Bone Joint Surg [Br] 1991;73-B:268-70.
19. Yamakado K, Kitaoka K, Yamada H, et al. Influence of stability on range of motion after cruciate-retaining TKA. Arch Orthop Trauma Surg 2003;123:1-4.

20. Warren PJ, Olanlokun TK, Cobb AG, Walker PS, Iverson BF. Laxity and function in knee replacements: a comparative study of three prosthetic designs. Clin Orthop 1994;305:200-8.

21. Insall JN, Ranawat CS, Aglietti P, Shine J. A comparison of four models of total knee replacement prostheses. J Bone Joint Surg [Am] 1976;58-A:754-65.

22. Bellamy N, Buchanan WW, Goldsmith $\mathbf{C H}$, Campbell J, Stitt LW. Validation study of WOMAC: a health status instrument for measuring clinically important patients relevant outcomes to antirheumatic drug therapy in patients with osteoarthritis of the hip or knee. J Rheumato/ 1988;15:1833-40.

23. Massin P, Gournay A. Optimization of the posterior condylar offset, tibial slope, and condylar roll-back in total knee arthroplasty. J Arthroplasty 2006;21:889-96.

24. Dejour D, Deschamps G, Garotta L, Dejour H. Laxity in posterior cruciate sparing and posterior stabilized total knee prostheses. Clin Orthop 1999;364:182-93.

25. Gogia PP, Braatz JH, Rose SJ, Norton BJ. Reliability and validity of goniometric measurements at the knee. Phys Ther 1987;67:192-5.

26. Mayerson NH, Milano RA. Goniometric measurement reliability in physical medicine. Arch Phys Med Rehabil 1984;65:92-4. 